\title{
Eradicating polio menace in Nigeria
}

\author{
Volume 4 Issue I - 2016
}

Keywords: Wild polio virus, Poliomyelitis, Eradicating, WPV, Paralytic poliomyelitis, Polio virus, NIDs, Nigeria, Infectious

Abbreviations: WPV, Wild Polio Virus; SIA, Supplementary Immunization Activities; OPV, Oral Polio Vaccine; NPI, Nigerian National Programme on Immunization; IPD, Immunisation Plus Days; VDPV, Vaccine Derived Polio Virus; NIDs, National Immunisation Days; mOPV, Monovalent Oral Polio Vaccines

\section{Introduction}

The main aim of eradicating Poliomyelitis is to provide fundamental health care services for practically all populations in the world, therefore the need to review the effectiveness of this health intervention for future planning of other related infant killer diseases in Nigeria.

\section{Description of poliomyelitis}

Poliomyelitis is a viral disease caused by wild polio virus (WPV), a member of the family picornaviridae. Poliomyelitis has been known for at least 3000 years, depictions of its invalidating effect have been discovered in Egyptian Frescos.

Polio virus is very stable and can remain infectious for relatively long periods in food and water, which are its main route of transmission before it invades the lymph nodes or sometimes enters the bloodstream where it persists to cause viremia. In majority of cases (99\%), clinical disease does not result while in minority of cases (1\%) enters the central nervous system where it causes paralytic poliomyelitis.

The disease is infective in the 10 days before and after appearance of the symptoms and affects children under the age of five years. Almost $100 \%$ of children and $90 \%$ of non-immune adults in the immediate family of a carrier may be contaminated, as estimates shows that on the average only one of every 200 infections results in paralysis, meaning that poliomyelitis may circulate silently for many months or years from patient to patient before a case of paralysis occurs. ${ }^{1}$

\section{Statement of the problem}

Majority of developed countries eradicated poliomyelitis in the 1980 s, thanks to oral polio vaccines developed in 1950s, but polio continued being endemic in the developing countries.

In 1988, polio was endemic in 125 countries and more than 350,000 cases of poliomyelitis were reported, in 2003, there were only 6 endemic countries, with only 784 cases being reported while 25 previous countries were re- infected between 2003-2005 due to import cases. ${ }^{2,3}$

Global report of WPV cases in 2005-2006 indicated that $830(42 \%)$ occurred in infants under 2 years with under 5 reporting $1,867(95 \%)$ and children with less than 3 dose of OPV recording 1,484 (76\%) with 69 cases of paralyses reported in Nigeria in 2007 due to mutation of a vaccine virus (MMWR, 2006).

\author{
Eloke Onyebuchi \\ Public health specialist, Onyibupet Consulting limited (A health \\ sector consulting), Nigeria
}

\begin{abstract}
Correspondence: Eloke Onyebuchi, Public health specialist/ Principal consultant, Onyibupet Consulting limited (A health sector consulting), Abuja, Nigeria, Tel +234 (0) 8166777।42, Email onyibupetconsulting@gmail.com
\end{abstract} Received: November 02, 2016 | Published: November II,
2016

In sub-Saharan Africa, Nigeria with 140 million populations in 2006 experienced new cases of polio in children less than 5 years in its northern region from August 2003-31 July 2004 as a result of interruption of polio immunization in the northern region. This occurrence resulted in increase of polio cases due to rainy season which spread the disease in the population and constituted the reinfection of 20 other free polio countries as polio cases continued to increase due to low vaccine distribution in Nigeria (MMWR, 2008; Margaret, 2008)

During 2008-2009, Nigeria was the source for WPV1 transmission to 11 countries and WPV3 transmissions to four countries. However,WPV3 cases rose approximately six -fold, from 51 during January-July 2008 to 303 during the same period in 2009 partly because of the increased emphasis on controlling WPV1 (MMWR, 2009). WPV in Nigeria continued to spread due to these factors; population size, climate and environmental conditions (Table 1).

Source: CDC - MMWR, 2009.

\section{Polio eradication in Nigeria}

Polio is set to be the second infection eradicated from the planet after smallpox. To ensure sustainability through community participation and ownership, Nigerian National Primary Health Care Development Agency (NPHCDA), formerly known as National Programme on Immunization (NPI) introduced supplementary immunization Activities (SIA) by replacing routine immunisation to immunisation plus days (IPD), during which combination of oral polio vaccine and inactivated polio vaccine are provided through house to house service delivery to improve coverage of oral polio vaccine (OPV) in hard to reach target populations with high incidence of poliomyelitis. This modified strategy is to develop the depreciating health system in the country by systematically surveying for other killer diseases and strengthening routine immunisation against polio by boosting population immunity in targeted age group to interrupt the importation of polio into the high risk population to deprive the virus from spreading. As Patriaca et al suggest that "Type 2 vaccine virus 
and enteric pathogens often interfere with responses to types 1 and 3 vaccine virus, allowing seroconversion, which might lead to Vaccine derived polio virus (VDPV) but this, may be overcome by modifying the absolute and relative dosage of the three Sabin types" (Patriaca et al. 1991). This argument was supported by other researchers, who claimed that "VAPP cases per million vaccinated can be prevented by increasing OPV schedule through immunization activities" (Caceres and Sutter, 2001).

Table I Number and percentage of non-polio acute flaccid paralysis (NPAFP) reported cases among children aged 6--59 months with zero dose* of oral poliovirus vaccine (OPV) --- Nigeria, January 2006--June 2009†

\begin{tabular}{|c|c|c|c|c|c|c|c|c|c|}
\hline \multirow{3}{*}{$\begin{array}{l}\text { Region/State } \\
\text { High-Incidence } \\
\text { Northern States }\end{array}$} & \multicolumn{3}{|l|}{2006} & \multicolumn{2}{|l|}{2007} & \multicolumn{2}{|l|}{2008} & \multicolumn{2}{|l|}{2009} \\
\hline & \multirow{2}{*}{$\begin{array}{l}\text { No. of NPAFP } \\
\text { cases } \\
974\end{array}$} & \multicolumn{2}{|c|}{ Zero dose } & \multirow{2}{*}{$\begin{array}{l}\begin{array}{l}\text { No. of } \\
\text { NPAFF }\end{array} \\
863\end{array}$} & Zero dose & \multirow{2}{*}{$\begin{array}{l}\text { No. of NPAFP } \\
\text { cases } \\
I, I 50\end{array}$} & $\begin{array}{l}\text { Zero dose } \\
\text { No (\%) }\end{array}$ & $\begin{array}{l}\text { No. of NPAFP } \\
\text { cases }\end{array}$ & $\begin{array}{l}\text { Zero dose } \\
\text { No(\%) }\end{array}$ \\
\hline & & 306 & $(3 I)$ & & $|8|(2 \mid)$ & & $210(18)$ & 547 & $60(\mathrm{II})$ \\
\hline Bauchi & 77 & II & (14) & 107 & $17 \quad(16)$ & 95 & $13 \quad(14)$ & 48 & $0 \quad(0)$ \\
\hline Jigawa & 124 & 56 & $(45)$ & 126 & $31 \quad(25)$ & 99 & $5 \quad(5)$ & 39 & $2 \quad(5)$ \\
\hline Kano & 247 & 95 & (38) & 214 & $68 \quad(32)$ & 364 & 107 (29) & 169 & $29(17)$ \\
\hline Katsina & 185 & 69 & (37) & 161 & $33 \quad(2 I)$ & 195 & $32 \quad(16)$ & 74 & $8 \quad(\mathrm{II})$ \\
\hline Yobe & 84 & 18 & $(2 I)$ & 62 & $10 \quad(16)$ & 96 & $2 \quad(2)$ & 76 & I (I) \\
\hline Zamfara & 143 & 28 & (20) & 68 & $(13)$ & 161 & $25 \quad(16)$ & 77 & $15(19)$ \\
\hline $\begin{array}{l}\text { Other Northern } \\
\text { States }\end{array}$ & 1,032 & 61 & (6) & 996 & $37 \quad(4)$ & 1,222 & $58 \quad(5)$ & 715 & $23(3)$ \\
\hline Total & 2,918 & 382 & (13) & 2,951 & $242(8)$ & 3,659 & 294 (8) & 1,948 & $95(5)$ \\
\hline
\end{tabular}

*Children who have never received an OPV dose, as reported by caregiver.

†Surveillance data are reported quarterly; complete data available only for January--June 2009.

§High-incidence states had $\geq 0.8$ confirmed WPV cases per 100,000 populations during 2008.

IAdamawa, Benue, Borno, Federal Capital Territory, Gombe, Kebbi, Kogi, Kwara, Nassarawa, Niger, Plateau, Sokoto, and Taraba.

**Abia, Akwa Ibom, Anambra, Bayelsa, Cross River, Delta, Ebonyi, Edo, Ekiti, Enugu, Imo, Lagos, Ogun, Ondo, Osun, Oyo, and Rivers.

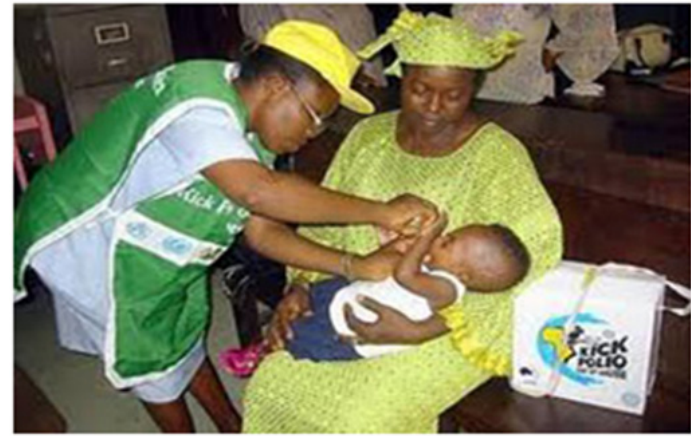

*Nigeria has to reach every last child to stop transmission of the wild polio virus. Photo: Courtesy of UNICEF.

As part of the "SIA" implementation, a rapid assessment of the immunisation services at the national and sub-national health facility level was conducted. These assessment revealed the weaknesses within the immunisation program and several factors cited as being responsible for this problems like lack of proper planning at Local and State levels, lack of up to date national immunisation policy and guidelines at the service delivery points, decreasing motivation of health workers, poor quality of services, frequent stock out of vaccines at local and national levels and low demand for services from the community were discovered to have contributed to the overall stagnation of the immunisation coverage. This was finally ameliorated, and a National strategy, which has produced ten rounds of National Immunisation Days (NIDs) between 1996 and 2000 was re- implemented. Since then, coverage has been increasing with $23 \%$ of children reached in 1999 who have never been reached before in many urban slums and hard to reach terrain. ${ }^{4}$
However polio eradication in Nigeria took another dimension in 2003 - 2004, when the northern part boycotted the immunisation against polio on the grounds that the vaccine was contaminated with HIV/AIDS while others argued on issue of health equity saying that Government have never introduced a free health policy like polio intervention in the past. Some evidenced based studies proved that even among the enlightened people, there is doubt about the importance of polio eradication when compared to other deadly diseases present in the country, which has been ignored by the Government (Ahmad 2004; Elisha, 2005). These boycott and other questions regarding vaccine safety triggered the government to test the OPV vaccines being used in the country in the presence of religious readers and other international partners (Ahmad, 2004). The result of the test proved the safety of the vaccine. This improved the uptake of the vaccine and immunisation coverage in some northern parts. Evidence from Jenkins et al..$^{5}$ on vaccine efficacies in Nigeria proved the effectiveness of the vaccine. Their evidence proved that successful eradication of poliomyelitis in Nigeria is not a vaccine safety issue but lack of improved vaccine coverage in the country. However, Jenkins et al. ${ }^{5}$ did not emphasize on probable cases of vaccine derived poliovirus (VDPV) which is suspected to be circulating in the country. "VDPV" case in the country is part of the reasons why the disease has not been eradicated. This is because the government cannot convince the population that the vaccine is safe and in the other hand announcing that the disease is still endemic based on the circulating "VDPV".

Supplementary immunisation became a successful campaign in Nigeria, because fixed strategy, now known as house to house service delivery has been strengthened and key strategies for improving the service delivery includes the following actions;

a. Development of a planning framework at central, states and Local council levels for the revitalisation of NPI services. 
b. Training (cascade and on- job) of immunisation health workers at all levels on all aspects of immunisation including adverse events following immunisation.

c. Reduction of geographical accessibility to immunisation centres within the sub-national levels. Re- allocation and establishment of new static centres for vaccine distribution.

d. Implementation of outreach mechanisms as an innovative approach for the hard to reach populations.

e. Identification and provision of the logistical support needed for effective implementation of services at the sub-national levels.

f. Provision of adequate supply of vaccines at the local health facility levels, regular support, supervision and review meetings to monitor progress of implementation of the plans, implementation of appropriate policies and strategy to reduce missed opportunities in reaching target groups and vaccine wastage.

g. Revision of the national policies on immunisation including the policy on injection safety, use of innovative mechanisms to improve personnel motivation, such as official recognition of merits, availing training and meetings opportunities.

This eradication campaign strategy to some extent reduced gender, caste and wealth based inequities because the intervention is provided free to the population. ${ }^{6}$ However this intervention has failed to reduce residence based and religious inequities in the country which is the major reasons why the disease has not been eradicated.

\section{Alternative Text}

The figure above shows the number of laboratory-confirmed poliomyelitis cases, by wild poliovirus (WPV) type or circulating vaccine-derived poliovirus type 2 and month of onset, type of supplementary immunization activity (SIA), and type of vaccine administered in Nigeria from January 2006 through July 2009. WPV1 is more likely to cause paralytic disease and have a wider geographic spread than WPV3. Monovalent oral polio vaccines (mOPV) are more effective against a given WPV type than is trivalent OPV (tOPV). Two national SIAs were conducted during 2008, one using monovalent OPV type 3 (mOPV3), and one using monovalent OPV type 1 (mOPV1). Three national SIAs were conducted during January-May 2009 using mOPV3, mOPV1, and tOPV, consecutively.

Source: CDC - MMWR, 2009.

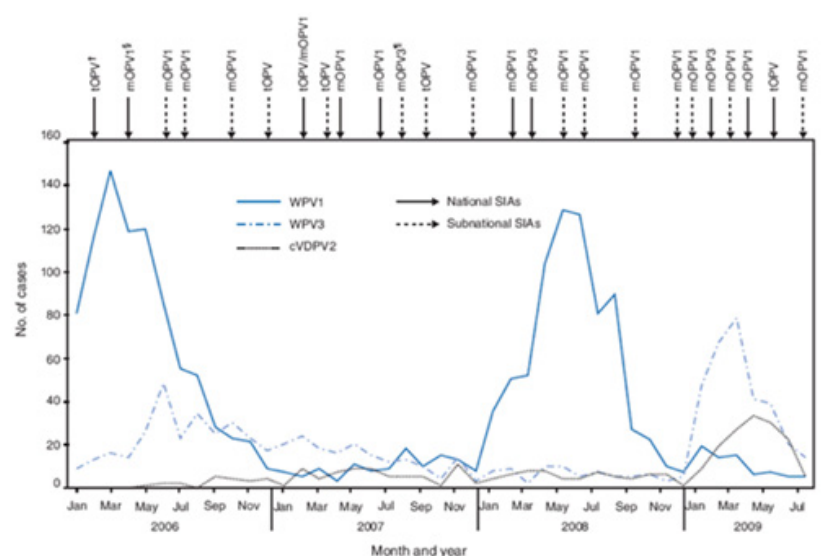

Figure I Number of laboratory-confirmed poliomyelitis cases, by wild poliovirus (WPV) type or circulating vaccine-derived poliovirus type 2 (cVDPV2) and month of onset, type of supplementary immunization activity (SIA),* and type of vaccine administered --- Nigeria, January 2006--July 2009.

\section{Conclusion}

Despite the recent setback on polio immunisation in the northern part of Nigeria, the initiative to eradicate polio in Nigeria has been a success and war against polio is being won, continued effort from the Government needs to be strengthened by taking the following action to improve coverage and possibly resolve the miss - clarification of information in Northern Nigeria. ${ }^{7-12}$

Recently, the former Minister of state for Health, Nigeria, Dr. Mohammed Ali Pate stated that "The doubt raised in 2003 and 2004 on vaccines by people who don't have scientific evidence are drawing us back. If people stop confusing parents to paralyse their children, we will not have polio cases again." He went further to state that Muslim children are dominated with the disease because of the refusal of their parents to produce them during National immunisation days, therefore, making up 98 percent of polio victims in the country (Daily trust, 06/03/2013).

Having said that, I strongly believe the former Honourable minister is a good player in this field as he is fully endowed with massive experience on polio eradication in Nigeria, having served as the Executive Director of National Primary Health Care Development Agency. But it appears the Minister has failed to recognize, that the drastic action, to close the gap of winning the war against polio in Nigeria, lies on using technical measures, rather than mere engagement campaigns, as the law of the country demands to counter this lack of evidence based statement on vaccines in 2003 and 2004 made by those people being referred to in his speech, as I believe Nigeria have a public health law, strongly guided by the constitution.

Nigerian Government should make these people either come out and justify their statement with a scientific evidence based facts on the vaccine or be held responsible for the death of the health workers and the children paralysed in that region. ${ }^{12-26}$ If these people successfully justify their statement with a scientific base, then it is left for the Nigerian Government to question the credibility of the vaccines from the producers. To that end, we would now arrive at a strategic measure on how to resolve the arguments and counter arguments on the safety of polio vaccine and possibly find the right way of eradicating poliomyelitis in Nigeria. This is because the way, we have the situation now, there will never be a solution to polio immunisation in Nigeria, if the minds of the people in that region is not is not made to believe on the reality of the safety of the vaccine. Applying the law against these people will serve as a lesson to others who might want to hide on inappropriate statements or unknown interest to jeopardise the effort of donors, Government agencies and practitioners that are wholly determined to eradicate poliomyelitis in Nigeria. This is because we have seen over the last years, the death of health care workers in the northern part of Nigeria, dominated by Muslims, simply because of the same fallacy on the safety of the vaccine. It is only when we use formative empowerment programmes or vigorous strategic measures, such as applying the law against these people to arrest further rumour, about the effectiveness of this vaccine, that we can successfully eradicate polio in Nigeria. Also, While the initiative to eradicate polio in Nigeria has been a success and war against polio is being won, continued effort from the Government needs to be strengthened by improving the following "gaps in provision" to add taste on coverage;

i. Sustainable ownership at the local government is highly variable. This is because the "war" on polio "will be won or lost at the local government level.

ii. Lack of active surveillance unit and follow up of probable cases at the local level. 
iii. The operational health system in Nigeria is not well run and organised. Therefore it makes the polio eradication strategies difficult to be implemented.

iv. Inadequate mobilisation in the community level, like women and local leaders is another barricade to creating community demand for polio eradication.

v. Inadequate strategic plan in maintaining the potency of the vaccine through "cold chain technique".

vi. The Federal Government should consider providing additional funds at the State and LGA level and issuing directives and guidelines to States and Local Governments to provide adequate funds according to the size of the target population, in order to achieve and maintain uniform and adequate immunization activities in the country.

\section{Acknowledgments}

None.

\section{Conflicts of interest}

None.

\section{References}

1. Burrows W. Textbook of Microbiogy. (20th edn), London, Sanders, Canada. 1973.

2. World Health Organisation. World health report. Make every mother and child count. 2005.

3. Centre for Disease Control and Prevention. Progress toward interruption of wild polio virus transmission. Morbidity and mortality weekly report. 2006.

4. Awosika. Boosting Routine Immunisation in Nigeria. Issues and proposed action points. 2000.

5. Jenkins H, Bruce R, Gasasira A, et al. Research Council (MRC), centre for outbreak analysis and modelling, Department of Infections and Disease Epidemiology, Faculty of Medicine, St. Mary's Campus, Imperial College London. Effectiveness of immunization against paralytic polio in Nigeria. 2008;359:1666-1674.

6. Bonu S, Rani M, Baker T The Impact of National Polio Immunisation Campaign on Levels and Equity in 2003.Immunisation Coverage. Evidence from Rural India. Social Science MED. Online 57: 1807-1819.

7. Ejiofor P. Basic Principles of Administration and Management. (2nd edn). Awka, Amaco. 1989.
8. Ballandin B. A manual for Medical Assistants and other Rural Health Workers. Nairobi. English press. 1985.

9. World Health Organisation. Global polio eradication initiative (GPEI). 2004

10. Centre for Disease, Prevention and Control. Progress towards Polio Eradication —— Nigeria. 2004-2005;54(35):873-877.

11. Calman K. The Potential for Health. How to improve the Nation's health. New York. Oxford, USA. 1998.

12. Donaldson L. Essential Public Health. (3rd edn). London: Radcliffe. 2001.

13. Ransome K. Primary health care in Nigeria. 1988.

14. Okoto JI. State of National Programme on Immunisation in Nigeria. 1990.

15. Kaprio. Health for all by the year 2000. The Role of Health Education. International journal of health education. 1979.

16. Sanford R, Wolfe R, Ilene B, et al. Addressing Immunisation Barriers, Benefits, and Risks. J Fam Pract. 2007;56(2 Suppl Vaccines):S61-S69.

17. FBA Health System Analysst. State of Routine Immunisation Services in Nigeria and Reasons for Current problems. 2005

18. National Programme on Immunisation. Strategic Plan of Action for the Eradication of Poliomyelitis. Abuja: NPI. 2000

19. World Health Organisation. Immunisation in Practice. A guide for health workers-updated edition. 2004.

20. Ebong RD. An Evaluation of Immunisation Coverage of Nigerian Army Depot: A case study of Zaria, Northern Nigeria. J R Soc Health. 1992;112(1):3-6.

21. World Health Organisation Publication March-September. Count Down to Polio Eradication in Nigeria. 2009.

22. Idris M. Cases of polio in Nigeria are dropping. BMJ. 2002;325:493

23. Raufiu A. Polio Cases Rise in Nigeria as Vaccine is Shunned for Fear of aids. BMJ. 2002;324:1414

24. Odusanya O, Ewan F, Ahonkhai V. Determinants of Vaccination Coverage in Rural Nigeria. 2016.

25. World Health Organisation. Global polio eradication initiative (GPEI). Polio eradication evaluation. 2008

26. Daily Trust Publication. Most polio, meningitis victims are Muslims. 2016. 